\title{
Addressing the Foundation of a Profession for Fostering New Hope - Dentistry in India!
}

\author{
Dr.Prem Anand Prabhakaran M.D.S. (Oral \& Maxillofacial Pathology) \\ Dental Clinics, City Clinics, Mahboula; State of Kuwait.
}

\begin{abstract}
Choosing an institution for pursuing higher education in dentistry has become a hectic job now due to the availability of a hand full of colleges in India; from which the choice of sifting out the best, for an inexperienced person will be confusing \& effortful. While investing huge amount of personal endeavors to compete with the hidden curriculums \& to maintain a steady financial state, there are going to be plenty of hurdles to deal with under the pressure of course completion, if the choice is not the right one. Once you come out, the chances of getting a job is almost nil at institutional levels \& it's not going to be the dream job that once you aspired for, irrespective of the institute, where you completed the graduation!
\end{abstract}

Keywords: commercialization in health education, ruinous competitions, toxic personalities, hidden curriculums, unacceptable professional behavior, dental education system in India.

DOI: $10.7176 / \mathrm{JEP} / 10-12-03$

Publication date: April $30^{\text {th }} 2019$

\section{Introduction \& Background:}

The concept of a system of training that our ancestors followed has a wide spectrum of coverage on the core framing of basic human values. This transfer of knowledge operated in a chain \& continued with no end in the gurukulums. Ancient gurukulums used to teach health sciences too. This system was operated in a place where the teacher lived with his family \& establishments to train the students, who joined there. There was transmission of knowledge from preceptors to students; students gradually would mould themselves to perfection; they finally went out to serve the society; this continued with no end to the tradition.

Today's society has deviated from its path somewhere, to a route that is totally sheltered under greed \& acquisition of wealth; which proportionately made its hit on the health education systems in the form of budding health care institutes. Changing trends in today's society made a wide range of available assess in health sector from ordinary clinics to private facilities with superlative comforts; the existence of later relies more on the handling \& generation of profit, in addition to the display of moral virtues. Thus commercialization in modern society made its thwack in education system as well as in clinical sector.

\section{Role of Parents in Trendy Competitions \& its Effects:}

Over the last twenty years, humanity has changed a lot in all its aspect of decision making, views on each subject, style \& pattern of living. Undertaking a career in the health sector has become a symbol of higher rank in the current society, at least for some \& that is easily attainable due to the abundance of flourishing institutes, which offer the same. Times have changed; today's society is more concerned with providing the best education to their children. The pathetic scenario is that, a percentage of the parents or guardians neglect the true ambitions of their children, turn a blind eye towards their dream career line or passion. Instead the emphasis on trendy competitions attracts the child, to what their parents want from them \& not exactly on, what the child is interested in.

Commercialization has promoted many intruders in, with no motivation \& interest, with no true craving for the subject. Some of such individuals become an impediment in the path of the genuine students, when they find substitute ways of compromising the academic pressure that is common for all. Such candidates disparage the value of course or its contents. The result will therefore also produce a group of people who will be ignorant about the credibility of job that they are doing \& it will reflect on anyone, who will be dealing with such individuals: situational variations apply: it can be a patient, a student, or a colleague. If there is an ethical misconduct reported from any health care professional towards a patient, a colleague, or a student/resident, that in turn has a direct impact on grading pattern on the institute, which qualified him. we should remember, 'the quality of health education must be evaluated by what it produces'. The change in the views of people is definitely going to have an impact on the current generation \& it will definitely affect the generations to come.

\section{The Loss of Peaceful Environment, Toxic Personalities \&Hidden Curriculum:}

Daunting is another form of subduing, where these uninterested, demotivated candidates keep someone who is genuine, under a sort of pin point for a long duration to cover up the vulnerable spots in own self. Experienced teachers, who have seen enough life, believe that the insecurity \& immaturity added up with childishness in handling personal intolerance to stress makes them do so. Such an environment generates confusion \& intimidation amongst other students, which makes a psychologically unsafe, compromised learning environment, which in turn 
never promotes creative thoughts, critical thinking \& confidence that is very necessary for improving \& learning as higher education systems are concerned.

The business theme has also changed a few of those who are a part \& parcel of the education system. Such characters are difficult to identify; the true picture of those personalities, one encounters only when we reach near the tip of iceberg. Jealous nature intermixed with hatred \& rivalry slowly breaks out from them towards those subjects, whom they feel are better than them in many aspects or sometimes the reasons will be unpredictable. They remain masked, until when an environment suited to their real existence encounters; there you can recognize $\&$ realize such toxic personalities. These self-centered individuals who lack honesty, compassion \& kindness will be totally unprofessional in the inner circle of life, which is totally unidentifiable. Looking back into the Hindu epics, we can see such a guru, Dronacharya, who demanded the right thumb as gurudakshina from a true disciple Eklavya, who is a keen sighted, talented archer than his favorites, is an ideal example for toxic personality behavior from a teacher.

For a favorable learning atmosphere, teacher-students/professional colleague's (junior/senior) relationships hold an influential outcome. This sort of personal interactions is especially true, when it comes for higher education like post-graduation \& research degrees; where they have to be in the department for a long duration as residents. This relationship is totally based on the personality quality of the guides, behavioral background of the colleagues $\&$ the self. If this turns upside down, then the hidden curriculum begins.

The origin of hidden curriculum always point towards a highly toxic leadership, whose yardstick never fits the place where they belong to. One of the studies came out from U.S. with an additional finding in BMJ, by Erika Frank et.al, states that a compromised emotional stability \& low job contentment are major factors that are associated with those who downgrade or exasperate others. Before moving ahead with the decision about higher studies, one must definitely be well aware about the existence of the concept of hidden curriculum atleast in some places. The in-house working environment depends upon the variations in emotional fluctuations of that person, especially if the power of decision making is there in them; resulting in unhealthy relational work skills \& ruinous competitions leading to organizational defilement with definite impacts on working systems; in addition to the creation of adversarial relationships.

Toxic personalities or even those who support such individuals, for their personal benefits affect the emotional wellness \& the learning capacity of other students leading to a psychologically unsafe or toxic environment. Kets de Vries explained that "some leaders go far beyond the abnormal ways of functioning ... they go off the deep end", this statement clear cuts the extremity of movement spectrum of such personalities. Covert type bullying, rhetorical enquires \& other less professional behavior's towards the victim were reported in different places. This in turn leads to humiliation and burnout of victims, which others from outside never can realize.

A toxic personality in many circumstances escape or hides, not because of their cleverness or smartness, instead due to strong will power \& high tolerance of victims, which they have gathered, when they find the hard earned price their parents /guardians paid for building up higher education or professional career, has far more value than personal sacrifices they made, thus they withstands; since majority of students come from families of varying levels of socioeconomic status. Not in all cases this is the scenario. The chances of relationship between some of the media reports on student suicides in various health sectors in general, addition to many unreported cases, which constitute a minor proportion, points towards such hidden curriculums \& toxic people, yet to be investigated \& studied. Those who withstand finally clear out pursuing the graduation after prolonged periods of time. Out of those who cross over these hurdles, a proportion of youngsters get along with futile of maladaptive coping approaches, along with a very less interest with their chosen career. Those who are unable to cope up, end up either in discontinuing the course or with the sacrifice of one's own life.

Prior to the entry for post-graduation or doctoral degrees, the students \& guides/professors should know about each other as they have to work together for years. Students should have the option of selecting a guide $\&$ at the same time, also an option to change the guide, if any unexpected events arise, as life is always not easy.

\section{What is really needed?}

Unacceptable professional behavior which affects the personality of each victim is a phenomenon seen throughout health education sector globally with highest incidents in Finland (75\%) followed by the U.S. (42\%) \& then the U.K. (10.5-38\%).Articles addressing these issues from India are very minimum since these issues always goes unnoticed, gets ignored as unwanted events or gets little attention. This article is an attempt done to provide an insight into these sorts of issues \& discusses the background circumstances, which promotes the occurrence of such issues in various levels of health sector.

A quality education means, it should promise the emotional well-being of each student, which in turn is very important for conceptual understanding, apt grasping \& explicit memory for proper social behavior in a professional environment. For providing such an education, we should have preceptors condensed with rich core values, who can really be a friend, a philosopher \& a guide. Victimized students always hide out of self-blame, shame \& embarrassments. Reports of run-away cases from institutions \& suicides are also adding density to these 
types of issues. Day to day academic issues \& interpersonal problems amongst post-graduates \& research scholars should be handled by experienced senior guides, by considering the facts that adult students have personal life responsibilities, in addition to the commitment they have with the work load \& stress associated with academic programmes.

A classical guide with high self-esteem \& passion, respects the art of teaching, love the area of his specialty, supports \& cares for the aspirants or trainees. These types of teaching professionals have a paramount importance in building up the best, by molding the better out from their students. The presence of such teachers as department heads will automatically ensure calm \& peaceful work environment thereby ensures quality education.

Completion of higher studies in health care sector requires several years of hardship, be it a psychological effort or financial burden; in addition to the tight schedule one has to undergo along with other personal commitments. The real tragedy one faces is lack of a respectable source of earning \& crisis in job attainment, after crossing all these hurdles. Subsistence with a white colour job alone is difficult, unless there is proficient financial security from other sources. Most of the fresher's are forced to follow doctoral degrees \& research oriented works for attaining stability \& security of profession; and a few others turn into unrelated fields \& settle. That is the reason why there is a reduction in the inflow to graduate \& post graduate courses of dentistry in India.

Since there is a rapid raise in the number of health academic institutions in the country, faculty training should be done as a mandatory part of higher academics at least at the beginning of teaching career in institutions at university level. Formal training programmes should be initiated to maintain standards of teaching doctors, since there is a wide range of difference exists between teaching \& lecturing. There should be regular work outs conducted for the building up of educational vitality \& training of academic institutions.

\section{Conclusion}

Never break your passion for whatever be the thought on your future career line; you should always go after your own quest for the choice of selecting a profession or career, not after or not for the sake of satisfying parent's/guardian's compulsion or wish. For a resident programme, one should always find out the best departments in various institutions famous for the specialty training in pursuing a master's or doctoral degree rather than the choosing from available institutions randomly. To a good extend, information collected from students or peers will help out knowing the departments locally \& also about options abroad.

Periodic assessments from blind surveys conducted amongst students or residents helps the higher authorities to reach out, if there is an issue to be solved. Articles addressing unacceptable professional behavior in health sector are very less from India. More standardized surveys or scientific investigatory studies are suggested in this field.

And finally, we should remember a bunch of degrees that we have pursued; the amount of stress \& hardship that one has undergone goes wane, if you are unable to win your bread with the same. It's not a fantasy going after something which never supports your life; at the end of the day, when you turn back, how you offered your service to the society \& how you lived your life is very important; not the number of degrees earned...

\section{References}

Kishor Patwardhan, Sangeeta Gehlot, Girish Singh, H. C. S. Rathore (2011), "The Ayurveda Education in India: How Well Are the Graduates Exposed to Basic Clinical Skills?" Evid. Based Complement Alternat Med. 2011:197391. [PubMed]

Menon I, Spudich A. (2010), “The Ashtavaidya physicians of Kerala: A tradition in transition”. J Ayurveda Integr. Med. 1:245-50. [PubMed]

Imrana Qadeer, Sunita Reddy (2013), "Medical tourism in India: perceptions of physicians in tertiary care hospitals". Philos Ethics Humanit Med. 8: 20. [PubMed]

Cohen JJ. (1998), "Leadership for medicine's promising future", Acad. Med. 73:132-7. [PubMed]

Anja Timm. (2014), 'It would not be tolerated in any other profession except medicine': survey reporting on undergraduates' exposure to bullying and harassment in their first placement year, BMJ.4 (7). [PubMed]

Mussel man LJ, Mac Rae HM, Reznick RK, Lingard LA. (2005), 'You learn better under the gun': intimidation and harassment in surgical education. Med Educ. 39(9):926-34. [PubMed]

Ogunsemi OO, Alebiosu OC, Shorunmu OT (2010), "A survey of perceived stress, intimidation, harassment \& well-being of resident doctors in a Nigerian Teaching Hospital", Niger J Clin. Pract.13(2):183-6. [ PubMed]

Gose M. (2009), "When Socratic dialogue is flagging: questions \& strategies for engaging students", J Coll Teach Learn. 57(1):45-49. [Taylor \& Francis Online]

Jolt H, Lehrfeld S, Ashley A, MM. (1994), "Refocusing health care management: education \& training for national health reform", Health Care Manag. 1(1):135-44. [PubMed]

Ms.Yogini S Barahate (2014), "Role of a Teacher in imparting Value-Education", IOSR Journal of Humanities \& Social Science.2279-0837:13-15. [Google Scholar]

Marco Tavanti. (2011), "Managing Toxic Leaders: Dysfunctional Patterns in Organizational Leadership \& How 
to Deal with Them”. Human Resource Management (HRM). 06:127-136. [Google Scholar]

Sanjay Kalra, Ambika Gopalakrishnan Unnikrishnan (2016). "Our journal: Arjuna's choice, Eklavya's voice”, Indian J Endocrinol Metab. 20(1): 3-4. [PubMed]

Paul Haidet, Howard F Stein (2006), "The Role of the Student-Teacher Relationship in the Formation of Physicians: The Hidden Curriculum as Process", J Gen Intern Med. 21(Suppl 1): 16-20. [PubMed]

Hafferty F.W. (1998)," Beyond curriculum reform: confronting medicine's hidden curriculum", Acad. Med. 73(4):403-7. [PubMed]

Goldman (2008), "Company on the Couch Unveiling Toxic Behavior in Dysfunctional Organizations", Journal of Management Inquiry. 17 (3) 226-238. [Google Scholar]

Erica Frank, Jennifer S Carrera, Terry Stratton, Janet Bickel, Lois Margaret Nora. (2006),'Experiences of belittlement \& harassment \& their correlates among medical students in the United States: longitudinal survey", BMJ.333 (7570): 682. [PubMed]

Seabrook MA. (2004), "Intimidation in medical education: students' \& teachers' perspectives.”, Stud Higher Educ. 29:59-74. [Taylor \& Francis Online]

Minford, Manning. (2017), "Current status \& attitudes to self-care training in UK medical schools." Journal of Compassionate Health Care. 4 (3). [Google Scholar]

Bardes CL. (2004), "Teaching, digression \& implicit curriculum”, Teach Learn Med. 16(2):212-4. [PubMed]

Stern DT. (1998), "In search of the informal curriculum: when \& where professional values are taught", Acad. Med. 73(suppl 10):28-30. [PubMed]

M.L.Germain. (2017), 'Narcissism at Work: Personality Disorders of Corporate Leaders', Springer.

Kirsty Foster, Chris Roberts (2016), "The Heroic \& the Villainous: a qualitative study characterizing the role models that shaped senior doctors' professional identity”, BMC Medical Education.16 (206).

A.Major. (2014)," To Bully \& Be Bullied: Harassment \& Mistreatment in Medical Education”, Virtual Mentor American Medical Association Journal of Ethics. 16(3) 155-160. [Google Scholar]

Imran N, Jawaid M, Haider I, Masood Z. (2010), "Bullying of junior doctors in Pakistan: a cross-sectional survey", Singapore Med J. 51(7):592. [PubMed]

Flynn, G. (1999). "Stop toxic managers before they stop you!”, Workforce, 78 (8): 40-44.

Okemakinde, T., Adewuyi, J. O., Alabi, C. O. (2013),"The Place of Teacher in National Development in Nigeria", European Journal of Humanities \& Social Sciences. 19 (1).

Seabrook MA. (2003) Medical teachers' concerns about the clinical teaching context. Med Educ. 37:213-22. [PubMed]

Adkoli BV, Sood R. (2009)," Faculty development \& medical education units in India: a survey", Natl Med J India. 22(1):28-32. [PubMed]

Cook V, Fuller JH, DE. (2010), Helping students become the medical teachers of the future-the Doctors as Teachers \& Educators (DATE) Programme of Bart's \& the London School of Medicine \& Dentistry”, London. Educ. Health (Abingdon). 23(2):415. [PubMed]

Wilkerson L, Irby DM. (1998), "Strategies for improving teaching practices: a comprehensive approach to faculty development”, Acad. Med. 73(4):387-96. [PubMed]

Patricia Tempski, Patricia L Bellodi, Helena BMS Paro, Sylvia C Enns, Milton A, Martins, Lilia B Schraiber (2012), "What do medical students think about their quality of life? A qualitative study", BMC Medical Education.12 (106). [PubMed]

Adkoli BV, Sood R. (2009), "Faculty development \& medical education units in India: a survey”, Natl 22(1):2832. [PubMed]

Shrea Kapoor, Shaunak Ajinkya, Pradeep R Jadhav. (2016), "Bullying Trends in Undergraduate Medical Students", Journal of Clinical \& Diagnostic Research.10 (2): 05-08. [PubMed]

Medical Council of India. (1996), "Report \& Recommendations of National Workshop on "Medical Education An Appraisal”, New Delhi: MCI. 4-5.

Wilkerson L, Irby DM. (1998), "Strategies for improving teaching practices: a comprehensive approach to faculty development”, Acad. Med. 73(4):387-96. [PubMed] 